\title{
Flipping the Classroom in Otolaryngology Residencies
}

\author{
William J. Kohler ${ }^{1}$, Nicole M. Favre ${ }^{2}$, Daniel C. O'Brien ${ }^{3}$, Michele M. Carr ${ }^{2}$ \\ 1. Biomedical Sciences, West Virginia School of Osteopathic Medicine, Lewisburg, USA 2. Otolaryngology, Jacobs \\ School of Medicine and Biomedical Sciences, University at Buffalo, Buffalo, USA 3. Otolaryngology-Head \& Neck \\ Surgery/Rhinology, University of Alberta, Edmonton, CAN
}

Corresponding author: Michele M. Carr, mmcarr2001@gmail.com

\section{Abstract \\ Objective}

To understand the use of the flipped classroom (FC) - learning core content prior to an academic session, with class time devoted to applying this content - in otolaryngology residency education.

\section{Methods}

An electronic survey of 107 otolaryngology program directors (PDs), including demographic details, the flipped classroom perception instrument (FCPI), and the otolaryngology programs' current use of FC.

\section{Results}

Forty-four (41\%) PDs completed the FCPI. Seventy-one point one (71.1\%) of respondents were male, $60 \%$ were 30-49 years, and the remainder were older. Sixty-two percent (62\%) had fellowships associated with their program, 21.7\% of programs used the FC model Very Often, 17.4\% Somewhat Often, 28.3\% Sometimes, 17.4\% Somewhat Rarely, 8.7\% Very Rarely, and 6.5\% Never.

Attitudes toward FC principles were positive with modes "strongly agree" for all, except for "online modules enhance learning" where the mode was "slightly agree" with significantly higher scores for PDs over age 50 than for those younger ( 4.17 vs. 3.63, $\mathrm{p}=0.033$ ). There were no other significant differences comparing male vs. female PDs, younger vs. older PDs, smaller vs. larger programs, programs with or without fellowships, programs with $100 \%$ vs. $<100 \%$ board exam pass rates, or programs in different geographical regions. The pre-class activity mean score was 4.34 (95\% CI 4.12-4.56) and the in-class mean score was 4.18 (95\% CI 3.99-4.37). There was no significant correlation between the likelihood of using a flipped classroom and attitude scores.

\section{Conclusion}

Received 06/18/2020 Review began 06/23/2020 Review ended 06/27/2020 Published 07/03/2020

๑) Copyright 2020 Kohler et al. This is an open access article distributed under the terms of the Creative Commons Attribution License CC-BY 4.0., which permits unrestricted use, distribution, and reproduction in any medium, provided the original author and source are credited.
PDs value both the pre-class and interactive in-class principles of FCs but only $37.8 \%$ of programs use FC often, suggesting that practical approaches to implementation in this group could improve education in this population.

Categories: Medical Education, Otolaryngology

Keywords: otolaryngology residency, otolaryngology training, medical education, flipped classroom, graduate medical education, curricular methods, program directors

\section{Introduction}

Traditionally, educational content is delivered in graduate medical education (GME) through expert lectures; however, resident workload limitations have presented a challenge to presenting a robust curriculum [1-2]. With the advent of online learning, a concept known as the flipped classroom (FC) has emerged. This consists of the delivery of educational content to students prior to the in-class activity, thus allowing the class itself to be devoted to the application of the material [3]. A common model is the distribution of online videotaped lectures prior to scheduled didactic sessions. The concept originated in undergraduate institutions and has been reported to have been used with success at the high school, undergraduate, and medical school levels, with respect to class attendance and participation [3-4]. Recent attempts to translate the FC model in a residency setting have seen success in pharmacy, internal medicine, and emergency medicine [2-3]. In an attempt to quantify the perceptions of this new model, the flipped classroom perception instrument (FCPI) was designed and validated with a traditional didactic-based internal medicine residency curriculum, yielding overall internal consistency reliability of 0.84 [3]. The aim of this investigation is to determine program director (PD) attitudes toward the utilization of FCs in otolaryngology residency education using the FCPI. 


\section{Cureus}

\section{Materials And Methods}

PDs from every allopathic otolaryngology residency program in the United States $(n=107)$ were sent an email inviting them to participate in a brief, anonymous survey. The survey questionnaire was created based on the FCPI, a measure of individual opinions of the model developed iteratively in the literature [5]. Study data were collected and managed using Research Electronic Data Capture (REDCap) hosted at West Virginia University [6-7]. REDCap is a secure, web-based platform designed to support data capture for research studies. Individuals were only able to complete the assessment once, and their responses were kept anonymous and confidential. The survey was sent out four times between November 2017 and January 2018. It included a seven-item Likert scale questionnaire, consisting of questions concerning three pre-class activities and four in-class activities. The pre-class activities included attitudes toward online modules and toward learning key content prior to class, while in-class activities measured attitudes toward in-class discussion, application, interaction, and team projects. PDs were also asked to provide basic demographic information, including age, gender, and time spent as a program director. Program parameters included the number of residents admitted yearly to the program, the number of full-time faculty present, the presence of fellows in the program, and geographic location in the United States.

This protocol was approved by the West Virginia University Institutional Review Board. Statistical evaluation was performed using IBM SPSS Statistics (Version 25.0, Armonk, NY: IBM Corp 2017).

\section{Results}

Of the 107 program directors determined to have met the survey criteria, 48 (45\%) responded to the survey and 44 (41\%) completed the FCPI. The demographics of the participating otolaryngology residency program director group are illustrated in Table 1 .

\begin{tabular}{|c|c|c|}
\hline Response & $\mathrm{N}$ & $\%$ \\
\hline \multicolumn{3}{|l|}{ Age of PD (years) } \\
\hline $30-49$ & 22 & 60.0 \\
\hline 50 or older & 17 & 40.0 \\
\hline \multicolumn{3}{|l|}{ Gender } \\
\hline Male & 27 & 71.1 \\
\hline Female & 12 & 28.9 \\
\hline \multicolumn{3}{|l|}{ Time as PD } \\
\hline Less than 2 years & 12 & 30.4 \\
\hline Greater than 2 but less than 5 & 8 & 21.7 \\
\hline Greater than 5 but less than 10 & 12 & 28.3 \\
\hline More than 10 years & 8 & 19.6 \\
\hline
\end{tabular}

TABLE 1: Program director (PD) demographics

A majority of otolaryngology PDs who responded were males (71\%), with most identifying themselves to be in the 30-49-year age group (60\%). Table 2 summarizes the demographics of each of the residency programs included in the survey. 


\section{Cureus}

\section{Response}

Number of residents admitted per year

2 or fewer

$2.5^{\star}$

3

5

Other

Number of full-time faculty in program

5 or fewer

6-10

$11-15$

$16-20$

21 or more

Region of United States

Midwest

Northeast

Southeast

Southwest

West
$\mathrm{N}$

$\%$

4.9

34.1

17.1

12.2

7.3

3

2.4

19.5

26.8

9.8

41.5

17

12

29.8

34.0

19.1

4.3

12.8

TABLE 2: Program demographics

Wide variation was observed in the number of residents admitted per year and the number of full-time faculty, with representation from each geographical region of the United States. Out of all of the programs, $62 \%$ had fellowships and $70 \%$ had a $100 \%$ American Board of Otolaryngology graduate resident pass rate over the last five years.

The PDs' individual perceptions of various aspects of the flipped classroom model are illustrated in Table 3. 


\section{Cureus}

\begin{tabular}{|c|c|c|c|c|c|}
\hline $\begin{array}{l}\text { Never } \mathrm{n} \\
(\%)\end{array}$ & $\begin{array}{l}\text { Very Rarely } \mathrm{n} \\
(\%)\end{array}$ & $\begin{array}{l}\text { Somewhat } \\
\text { Rarely n (\%) }\end{array}$ & $\begin{array}{l}\text { Sometimes } \mathrm{n} \\
(\%)\end{array}$ & $\begin{array}{l}\text { Somewhat } \\
\text { Often } \mathrm{n}(\%)\end{array}$ & $\begin{array}{l}\text { Very Often n } \\
(\%)\end{array}$ \\
\hline $\begin{array}{l}\text { Have utilized a flipped classroom in this } \\
\text { residency program }\end{array}$ & $4(8.7)$ & $8(17.4)$ & $13(28.3)$ & $8(17.4)$ & $10(21.7)$ \\
\hline \multicolumn{6}{|c|}{$\begin{array}{l}\text { Question stem: Please indicate how much you agree with the following statements, considered in the context of residency training in your } \\
\text { program }\end{array}$} \\
\hline Means of enhancing learning & $\begin{array}{l}\text { Strongly } \\
\text { Disagree (\%) }\end{array}$ & Disagree (\%) & Neutral (\%) & Agree (\%) & $\begin{array}{l}\text { Strongly } \\
\text { Agree (\%) }\end{array}$ \\
\hline \multicolumn{6}{|l|}{ Pre-class } \\
\hline Online modules enhance learning & 0 & 2 & 33 & 42 & 22 \\
\hline $\begin{array}{l}\text { Learning key content prior to class sessions enhance } \\
\text { learning }\end{array}$ & 2 & 0 & 4 & 22 & 71 \\
\hline $\begin{array}{l}\text { Combination of online modules with in-class application } \\
\text { enhance learning }\end{array}$ & 0 & 2 & 27 & 31 & 40 \\
\hline \multicolumn{6}{|l|}{ In-class } \\
\hline Interactive applied in-class activities enhance learning & 2 & 0 & 7 & 29 & 62 \\
\hline In-class application of core content enhances learning & 2 & 0 & 4 & 33 & 60 \\
\hline Discussion of core content & 2 & 0 & 7 & 27 & 64 \\
\hline Team projects enhance learning & 2 & 7 & 24 & 31 & 36 \\
\hline
\end{tabular}

TABLE 3: Program responses regarding flipped classroom

Regarding the frequency of flipped classroom use in their programs, 10 (21.7\%) otolaryngology PDs replied "Very Often", 8 (17.4\%) replied "Somewhat Often", 13 (28.3\%) replied “Sometimes", 8 (17.4\%) replied "Somewhat Rarely", 4 (8.7\%) replied "Very Rarely", and 3 (6.5\%) replied "Never". Of the seven statements on the FCPI, PDs most frequently agreed that "Learning key content prior to class sessions enhances learning" (71\%), while "Team projects enhance learning" (36\%) was the most frequently disputed response. Attitudes toward FC principles were positive with modes "Strongly Agree" for all, except for "online modules enhance learning" where the mode was "Slightly Agree," with significantly higher scores for PDs over age 50 than for those younger ( 4.17 vs. 3.63, $\mathrm{p}=0.033$ ). There were no other significant differences for these principles when comparing male vs. female PDs, younger vs. older PDs, smaller (less than three residents per year) vs. larger (three or more residents per year) programs, programs with or without fellowships, programs with $100 \%$ vs. $<100 \%$ American Board of Otolaryngology exam pass rates, or programs in different geographical regions. Pre-class activity mean score was 4.34 (95\% CI 4.12-4.56) and the in-class mean score was 4.18 (95\% CI 3.99-4.37). There was no significant correlation between the likelihood of using a flipped classroom and mean attitude scores.

\section{Discussion}

With limitations to resident work hours and the need to balance time spent studying didactic material with patient care, the FC model may present a unique solution to maximize the effectiveness of instructional time. In an ideal medical education scenario presented by Prober and Khan, medical education is divided into three phases: building a framework of core knowledge, embedding knowledge through interactive formats, and encouraging the in-depth processing of specific knowledge [8]. The framework stage consists of the use of readily available materials for self-study, which could include written material, videos, or other electronic presentations. This is followed by an application of the previously learned material in the interactive stage such as in case discussions or problem-solving [8]. This approach is applicable in the realm of graduate medical education. Critics suggest that the differing nature of undergraduate and graduate medical education may limit the value of FC for residents. Due to emergencies relating to patient care and other clinical commitments, residents are not able to be continually invested in mastering the curriculum, making them less likely to engage with the pre-class material [1]. Preparation before an academic meeting may not be prioritized and thus not occur, as Young et al. found in their study with emergency medicine residents [2]. Their group ran two FC trials: in the first, only $64 \%$ of residents watched the video ordered before the teaching session, but in the second trial, $85 \%$ had done so [2]. In contrast, Burns suggests that an 
FC model may be ideal when limited duty hours discourage resident attendance at scheduled didactic sessions [9]. From a teaching clinician perspective, the FC model is attractive; clinicians may prefer to use already available online teaching resources, or record their own, with a better chance that every resident in their program will be able to use it at some point - not missing educational opportunities due to vacation, illness, duty-hour restrictions, or fatigue. Another opportunity with this model is the possibility of developing national, collaborative teaching resources such as the online free EKG interpretation course developed for Emergency Medicine residents and described by Burns et al. [10]. As well, with the ACGME Milestones program [11], academic clinicians need to spend better quality educational time with trainees in order to evaluate them on various parameters of their medical knowledge. This is more easily done in a case discussion or problem-solving session than in typical lecture situations.

FC usage has been demonstrated to improve long-term retention of information in residents [12]. In a cohort of PGY-3 pediatric emergency medicine residents, an FC model combined with interactive application-style questions led to improved scores on core pediatric emergency medicine topics [12]. Blair et al. did pre-tests and post-tests followed by a six-month follow-up test and found an improvement after their FC trial in internal medicine residents; however, there was no control group [13]. In similar fashion to the FC model, supplemental videos made available to otolaryngology residents but not scheduled in the curriculum and not made part of an FC paradigm led to improved scores on junior residents' otolaryngology in-training examinations in the pediatric otolaryngology, otology, and facial plastic surgery sections [14]. Otolaryngology residents have access to numerous on-line educational videos through the American Academy of Otolaryngology-Head and Neck Surgery [15] and those created by new multi-institution collaboratives [16-17], which may form the base for an FC program in this specialty.

In addition to improved empirical measures of academic performance, first-year obstetrics and gynecology residents who had taken an elective program in their fourth year reported the highest satisfaction in the FC portion of the course, to which they also attributed their improved clinical confidence as compared to the traditional didactic portion [18]. Program interest similarly increased in a surgery core clerkship, with students participating in FC sessions indicating higher career interest and learner satisfaction, although with identical standardized test performance [19]. Our survey results corroborate with the overall positive perception of FC implementation previously seen in the literature. However, the finding of older program directors more strongly supporting the FC model contrasts with previous literature, in which younger female PDs of internal medicine residency programs were more likely to perceive FC as favorable [3]. Cooper et al. noted that at the time of their work, measures of FCs were based on satisfaction alone, and studies had failed to address the feasibility of modifying the existing curriculum [1]. Recent meta-analyses note heterogeneity, high risk of bias, and lack of rigor in studies on FC, making it difficult to draw conclusions about its academic value [19-20]. Perhaps examining contributions of budget, resources, and receptive faculty in future studies could lead to increased accessibility and improved PD willingness to flip the classroom in otolaryngology.

The limitations of our study include the small sample size, although this response rate is typical of otolaryngology PDs in recent publications and in our experience [21]. We surveyed only PDs and may have found different results if residents or other faculty were queried. The questionnaire we used examined attitudes only, so barriers to the institution of this curricular method were not evaluated.

\section{Conclusions}

This study highlights the attitudes, perceptions, and use of the FC model among allopathic otolaryngology residency PDs, which were determined using the FCPI. Roughly two-thirds of PDs indicated that they had used the FC model at least sometimes, with a majority supporting the principles of enhanced pre- and inclass learning associated with the model. Despite having a positive outlook on the components of the FC and having very limited curricular time in the entire otolaryngology residency, FC is not universally employed by these educators. Future work should be directed toward maneuvers that may facilitate the incorporation of FC in otolaryngology residency.

\section{Additional Information \\ Disclosures}

Human subjects: Consent was obtained by all participants in this study. West Virginia University Institutional Review Board issued approval 1707655645. This study protocol was reviewed by the WVU IRB and approved as an exempt study. Animal subjects: All authors have confirmed that this study did not involve animal subjects or tissue. Conflicts of interest: In compliance with the ICMJE uniform disclosure form, all authors declare the following: Payment/services info: Funding: Research reported in this publication was supported by the National Institute of General Medical Sciences of the National Institutes of Health under Award Number 5U54GM104942-04. The content is solely the responsibility of the authors and does not necessarily represent the official views of the National Institutes of Health. Financial relationships: All authors have declared that they have no financial relationships at present or within the previous three years with any organizations that might have an interest in the submitted work. Other relationships: All authors have declared that there are no other relationships or activities that could appear to have influenced the submitted work. 


\section{References}

1. Cooper A, Hsieh G, Kiss J, Huang G: Flipping out: does the flipped classroom learning model work for GME? . J Grad Med Ed. 2017, 9:392-393. 10.4300/JGME-D-16-00827.1

2. Young TP, Bailey CK, Guptill M, Thorp AW, Thomas TL: The flipped classroom: a modality for mixed asynchronous and synchronous learning in a residency program. West J Emerg Med. 2014, 15:938-944. 10.5811/westjem.2014.10.23515

3. Bonnes SL, Ratelle JT, Halvorsen AJ, et al.: Flipping the quality improvement classroom in residency education. Acad Med. 2017, 92:101-107. 10.1097/ACM.0000000000001412

4. Sharma N, Lau CS, Doherty I, Harbutt D: How we flipped the medical classroom. Med Teach. 2015, 37:327330. 10.3109/0142159X.2014.923821

5. Wittich CM, Agrawal A, Wang AT, et al.: Flipped classrooms in graduate medical education: a national survey of residency program directors. Acad Med. 2017, 93:471-477. 10.1097/ACM.0000000000001776

6. Harris PA, Taylor R, Thielke R, Payne J, Gonzalez N, Conde JG: Research electronic data capture (REDCap)a metadata-driven methodology and workflow process for providing translational research informatics support. J Biomed Inform. 2009, 42:377-381. 10.1016/j.jbi.2008.08.010

7. Harris PA, Taylor R, Minor BL, et al.: The REDCap consortium: building an international community of software platform partners. J Biomed Inform. 2019, 95:103208. 10.1016/j.jbi.2019.103208

8. Prober CG, Khan S: Medical education reimagined: a call to action. Acad Med. 2013, 88:1407-1410. 10.1097/ACM.0b013e3182a368bd

9. Burns J: Critical care in the age of the duty hour regulations. Circadian-based scheduling, standardized handoffs, and the flipped classroom?. Crit Care Med. 2012, 40:3305-3306. 10.1097/CCM.0b013e31826bf117

10. Burns WP, Hartman ND, Weygandt PL, Jones SC, Caretta-Weyer H, Moore KG: Critical electrocardiogram curriculum: setting the standard for flipped-classroom EKG instruction. West J Emerg Med. 2019, 21:52-57. 10.5811/westjem.2019.11.44509

11. Accreditation Council for Graduate Medical Education. Milestones . (2020). Accessed: June 7, 2020: https://www.acgme.org/What-We-Do/Accreditation/Milestones/Overview.

12. Rose E, Claudius I, Tabatabai R, Kearl L, Behar S, Jhun P: The flipped classroom in emergency medicine using online videos with interpolated questions. J Emerg Med. 2016, 51:284-291. 10.1016/j.jemermed.2016.05.033

13. Blair RA, Caton JB, Hamnvik OR: A flipped classroom in graduate medical education. Clin Teach. 2019, 17:195-199. 10.1111/tct.13091

14. Cabrera-Muffly C, Bryson PC, Sykes KJ, Shnayder Y: Free online otolaryngology educational modules: a pilot study. JAMA Otolaryngol Head Neck Surg. 2015, 141:324-328. 10.1001/jamaoto.2015.41

15. American Academy of Otolaryngology-Head and Neck Surgery. Resident resources: Academy U . (2020). Accessed: January 20, 2020: http://www.entnet.org/residenteducation.

16. University of Kentucky College of Medicine. Corona initiative . (2020). Accessed: June 7, 2020: http://entcovid.med.uky.edu/ent-covid-past-videos.

17. University of Southern California Collaborative Multi-Institutional Otolaryngology Residency Education Program. Past videos. (2020). Accessed: June 7, 2020: https://sites.usc.edu/ohnscovid/pastvideos/.

18. Morgan H, Marzano D, Lanham M, et al.: Preparing medical students for obstetrics and gynecology milestone level one: a description of a pilot curriculum. Med Ed Online. 2014, 19:[Epub]. 10.3402/meo.v19.25746

19. Liebert CA, Lin DT, Mazer LM, Bereknyei S, Lau JN: Effectiveness of the surgery core clerkship flipped classroom: a prospective cohort trial. Am J Surg. 2016, 211:451-457. 10.1016/j.amjsurg.2015.10.004

20. Gillette C, Rudolph M, Kimble C, Rockich-Winston N, Smith L, Broedel-Zaugg K: A meta-analysis of outcomes comparing flipped classroom and lecture. Am J Pharm Educ. 2018, 82:6898. 10.5688/ajpe6898

21. Chen KS, Monrouxe L, Lu YH, Jenq CC, Chang YJ, Chang YC, Chai PYC: Academic outcomes of flipped classroom learning: a meta-analysis. Med Educ. 2018, 52:910-924. 10.1111/medu.13616 